\title{
Adverse Childhood Experiences (ACE) Among Prolific Young Robbery Offenders in London: Targeting Treatment for Desistance?
}

\author{
Lorraine Hilder $^{1} \cdot$ Heather Strang ${ }^{2} \cdot$ Sumit Kumar
}

Accepted: 15 November 2021 / Published online: 29 November 2021

(C) The Author(s) 2021

\begin{abstract}
Research Question How prevalent are various types of adverse childhood experiences among prolific young robbery offenders in London, with what implications for treatment and desistance of these people from serious offending?

Data Of the 1249 suspects under 26 years of age who were arrested for robberies in London in 2019, 81 (6.5\%) of them had been arrested for four or more robberies, totalling $24 \%$ of all robbery arrests of that age group (465 out of 1936). Of those 81 arrestees, 65 of them (80\%) percent had used a knife or threatened with a knife to commit their crime. In total, the 81 had criminal histories as suspects in 939 offences covering 34 offence types, most commonly theft from person (201), possession of drugs (164) and violence with injury (89).

Methods This study gathered extensive life history data for the 81 , with a special emphasis on adverse childhood experiences (ACE) including criminal victimisation by parents or other adults. The analysis compares the prevalence of ACE in the most prolific young robbery suspects to prevalence in general population samples.

Findings The 81 prolific robbery offenders had extremely high prevalence of ACEs: $80 \%$ had previously been victims of crime themselves (highest offence categories assault with bodily harm, robbery and domestic violence). Reported to police as missing is $63 \%$, school exclusions $49 \%$, incarceration of a family member $35 \%$ and known to social services $91 \%$. The prevalence of 4 or more ACEs among the 81 prolific robbery offenders is two to five times higher than it is in other estimates for London (random sample) or England (children in need).
\end{abstract}

Conclusions A substantial proportion of all London arrests for robbery identify young people with disproportionately high levels of adverse childhood experiences. Most of the ACEs are to some extent treatable by cognitive behavioural therapies and related treatments aimed at post-traumatic stress disorder (PTSD). One possible pathway to promote desistance from high-harm crime in this population may be the development and testing of a police role in helping to ensure that these few most chronic, high-harm arrestees received effective treatment for the consequences of ACEs.

Extended author information available on the last page of the article 
Keywords Robbery $\cdot$ Adverse childhood experiences (ACEs) $\cdot$ Victim offenders

\section{Introduction}

The commission of crime is heavily concentrated among a 'felonious few' offenders (Sherman, 2007). This finding has been observed across multiple samples and nations (Farrington et al., 2001), in both official records and self-reported offending (Wikstrom et al. 2012). It has long been recognised that there are certain risk factors associated with these concentrations that could be targeted against crime in general at an early age (Farrington et al., 2001), but governments have generally failed to provide the major funding required. From much available evidence, the patterns of concentration appear to be sustained over time.

A less expensive way to disrupt this concentration might be less preventive than early-childhood interventions, but still more effective than relying entirely on the criminal justice system. That alternative would be to identify the most prolific offenders in late adolescence who are already well-known to commit a disproportionately high rate of serious crimes, such as robbery with weapons. Once such a population is identified, it could be examined retrospectively for risk factors that could be altered, prospectively, by interventions.

The first two steps in such a strategy would be to (1) identify a group of young offenders with a high concentration of serious violent crime and (2) identify any and all treatable risk factors that are highly prevalent in such a group. Once those risk factors are known and understood, there may be treatments that could be mobilised by police and other offender managers as part of a problem-solving approach to the individuals concerned. The application of such treatments, such as cognitive behavioural therapy (CBT) for post-traumatic stress disorders, could be compared to standard criminal justice responses in a prospective randomised trial. CBT has been proven effective (Foa \& Meadows, 1997) at reducing, for example, PTSD among rape victims, even up to two decades after a crime victim has been raped. Given a high prevalence of childhood sexual assault victimisation among adolescent violent offenders, the relevance of successful PTSD treatments for those victims may be highly relevant to the prevention of robbery committed by those victims.

Before designing such a prospective trial, however, it is essential to retrospectively identify the risk factors associated with a large enough group to enrol in a test sample. The purpose of the present study is to do just that.

\section{The London Robbery Arrestee Cohort 2019}

The focus of this study is a cohort of all prolific young (age 25 and under) street robbery offenders arrested in London in 2019. It assembles the information held on Metropolitan Police Service (MPS) databases on both their victimisation and offending. Of all 1249 offenders aged under 26 who were charged with robbery in 2019, 81 of them $(6.5 \%$ of the 1249$)$ had been arrested for four or more separate robberies in 
that year (comprising $24 \%$ of all those robberies leading to arrests of persons under 26). It is those 81 young people who are the subject of this study.

The study explores what police and other records show about the socio-demographic characteristics of this cohort, as well as their offending and victimisation histories of this cohort.

\section{Adverse Childhood Experiences}

The study also examines what these records reveal about events meeting the accepted definition of adverse childhood events (ACEs) in their lives. ACEs do not have a legal definition, but the study applies a list of traumatic events or circumstances occurring before the age of 18 that studies indicate are associated with a variety of adverse physical and/or mental health outcomes in adulthood (Felitti et al., 1998, Asmussen, 2020).

These events were first identified by Felitti et al. (1998) in a study of almost ten thousand adult patients who were members of a large Health Maintenance Organisation (HMO) in San Diego. The 9,508 respondents were $71 \%$ of adults asked by the HMO to complete a standardised medical evaluation. Felitti et al. found that those respondents who had experienced four or more ACEs were between four and twelve times more likely to be alcoholics, drug abusers, heavy smokers, or obese than those who had not. The following list of events is comprised of what are now widely recognised ACEs:

- Physical abuse

- Sexual abuse

- Psychological abuse

- Physical neglect

- Psychological neglect

- Witnessing domestic abuse

- Having a close family member who misused drugs or alcohol

- Having a close family member with mental health problems

- Having a close family member who served time in prison

- Parental separation or divorce on account of relationship breakdown

Since Felitti et al.'s seminal study, a number of criminological studies have investigated the links between ACEs and criminal behaviour (Baglivio et al., 2014, Fox et al., 2018, Malvaso et al., 2018, Craig et al., 2021). All of these studies show that the ACE factors identified by Felitti et al. are more commonly found in criminal justice populations than in other groups. In the UK, using the 411 males born in London in the 1950s who were enrolled in the longitudinal Cambridge Study in Delinquent Development, the presence of ACE factors was found to have serious consequences for increased offending through the life course (Craig et al., 2017).

This study examines what Metropolitan Police Service (MPS) and linked records reveal about the experience of such adverse events in the lives of the 81 most-prolific 
young robbery offenders of 2019. The results of the study raise major questions about the implications for a police-led robbery prevention strategy.

\section{Research Question}

The research question for this study is embedded in the larger issue of how to deflect a small number of the most prolific young offenders from serious, violent and chronic offending. The specific question for this study is this:

How prevalent are various types of adverse childhood experiences among prolific young robbery offenders in London, with what implications for treatment and desistance of these people from serious offending?

\section{Data}

Three Metropolitan Police Service data sources were used to capture the data for this study:

1. CRIS (Crime Recording Information System): In CRIS, the MPS records all crimes reported in its jurisdiction, together with the progression of these crimes from reporting to any arrests and ultimate case disposal. It also records details of any suspect or accused persons.

2. IIP (Integrated Intelligence Platform): The IIP system draws together data and intelligence reports from several MPS databases including MERLIN which records police interactions with children and vulnerable adults that are shared with safeguarding teams to assess risk and to assist in a multi-agency approach.

3. PNC (Police National Computer): The computer system for England and Wales that is used by police to store information on people who have been convicted, cautioned or recently arrested. It includes their aliases, fingerprints and DNA and also stores wanted or missing information and other intelligence sources.

Figure 1 shows the process by which the 37,043 personal street robberies in London recorded on CRIS as occurring in 2019 eventually yielded 81 who had been identified and accused of four or more robberies in that year. It is these 81 who form the data set for this study. They all had prolific victimisation and offending histories: In total, the cohort of 81 had over 14,000 entries on the IIP.

The available data on these 81 offenders were then recorded on two Excel data bases: one recorded their offending and the other their victimisation including ACEs, trauma and other relevant factors. They were later combined for descriptive and statistical analysis.

MPS records were searched for indications of the ACE factors identified by Felitti et al. (1998). These ten categories, however, were reduced to nine for this study; 'psychological neglect' was not included as police officers are not qualified to make this assessment. Many other negative circumstances in children's lives are also associated with poor outcomes as adults, however (Welsh and Farrington, 2006). Eight 


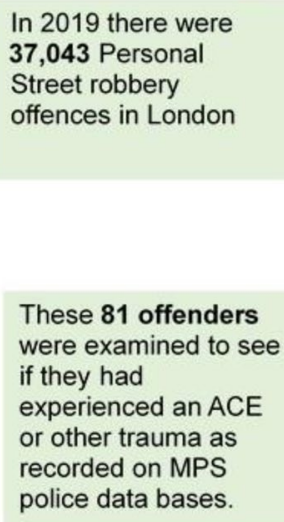

Study removes commercial and domestic crime related robberies, and any offenders that are aged over 25.

Fig. 1 Data selection process

additional factors were therefore considered as they were consistently available from the police records and seem relevant in understanding the lives of these offenders. These factors were as follows:

- Members of their family have a criminal history

- Experienced the death of a parent or sibling

- Believed to be part of county lines ${ }^{1}$ network

- Believed to be part of a gang ${ }^{2}$

- Has been a missing person

- Has been excluded/expelled from school

- Uses drugs

- Has a physical or mental health disability

There were a number of limitations on the reliability and completeness of these data. For example, a quarter of robbery offenders recorded on CRIS had no PNC record, so manual checks were made on all 81 offenders in the data set to ensure all their offending history was captured. The IIP has no facility to identify high harm cases and, like all MPS systems, does not join up family members. Currently, MPS systems do not have this capability, and the new MPS Connect data system cannot be amended to include ACE and trauma factors.

\footnotetext{
1 County Lines is a term used by government departments and partner agencies to describe the use of mobile phone 'lines' by gangs looking to extend their drug dealing activities into locations outside their metropolitan home areas. The areas targeted are commonly more rural 'county' towns (UK Home Office, 2017).

2 If included on the MPS, Gangs database or gang activity is recorded on the criminal intelligence database CRIMINT, the MPS intelligence report platform.
} 
There was much missing data around dates of birth and other demographic details, all of which was carefully cross-checked. As the study used a binary counting report of ACE's-yes/no for each factor-it was essential to conduct a full intelligence picture by reading all IIP entries. In total, officers working on this study read over 14,000 reports. The team extracting the data was also conscious that merely counting the number of ACEs does not reveal or quantify the full extent, severity or frequency of trauma and adversity experienced. For example, an MPS report may state that there was no food in the house but give no further explanation or detail that might contribute to assessing needs. Officers inputting these data are not trained to make such assessments or given guidance on what they ought to include in reports, so the team did not attempt to interpret the severity of the ACEs experienced.

In creating ACE records for the cohort of 81, all police officers in the team involved in reviewing the data were conscious of data validation. For inter-rater reliability, the team met regularly to discuss how they reached decisions particularly relating to emotional abuse. Also, dip sampling of the cohort was employed where all of the team would completely check on the same individuals to ensure reliability and completeness.

\section{Methods}

The research methodology of this study was a two-step process. First, the data resources described above were searched to compile as complete a description as possible of the ACE history of the 81 prolific young robbery defendants, with the prevalence of each category of ACE computed for that population. Second, the available research literature on the same ACE categories in the general population was examined, in order to determine whether the ACE prevalence was substantially higher among the 81 young robbery defendants than among the general population estimates.

\section{Findings}

We begin by examining the characteristics of the 81 offenders in the data set-all under 26 years old and all arrested for four or more street robbery offences in the year 2019. We then review what the data reveal about their experience of ACEs, together with the eight additional pieces of information available in police records which can add to the picture of their life experiences. Finally, we compare the prevalence of specific ACEs in the 81 to the same ACE categories as reported in other populations, to the extent possible given differing periods of time at risk.

\section{Demographic Characteristics: Age, Gender and Ethnicity}

Figure 2 displays the percentage of the 81 offenders in 2019 by their age in that year. This distribution is consistent with other findings on life course offending (Farrington, 1986; Loeber \& Howell, 2012) with peak offending at around 15-16 years of age followed 


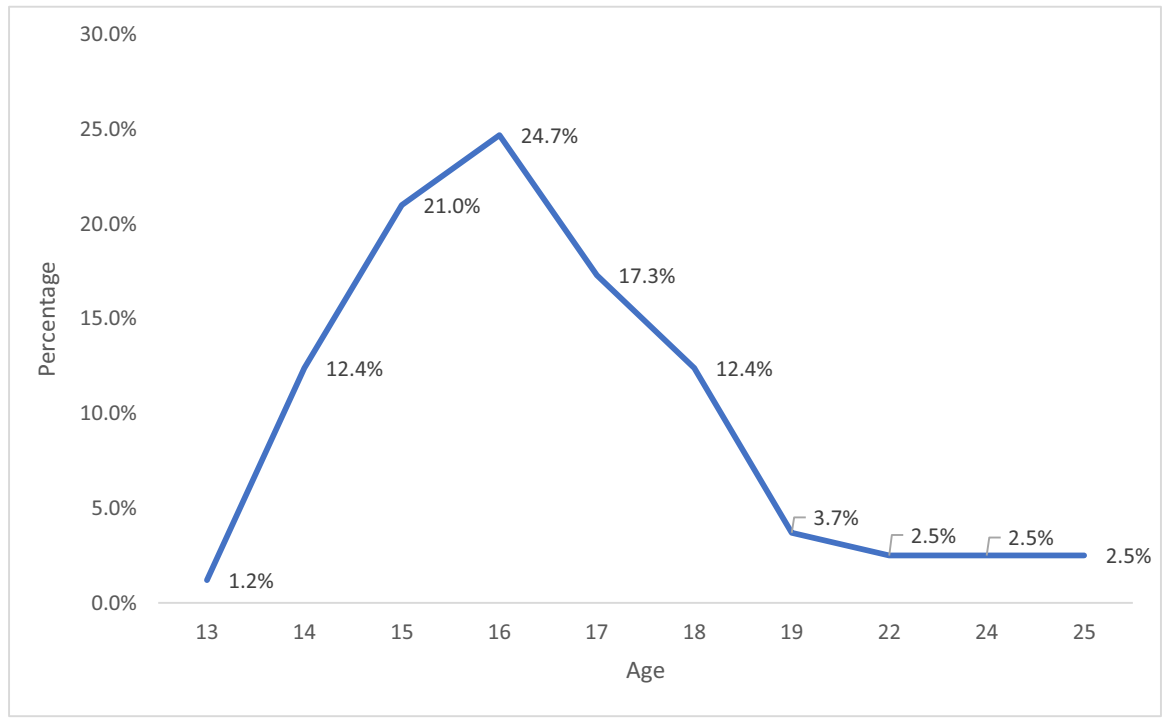

Fig. 2 Percentage of cohort's 81 offenders in 2019 by age

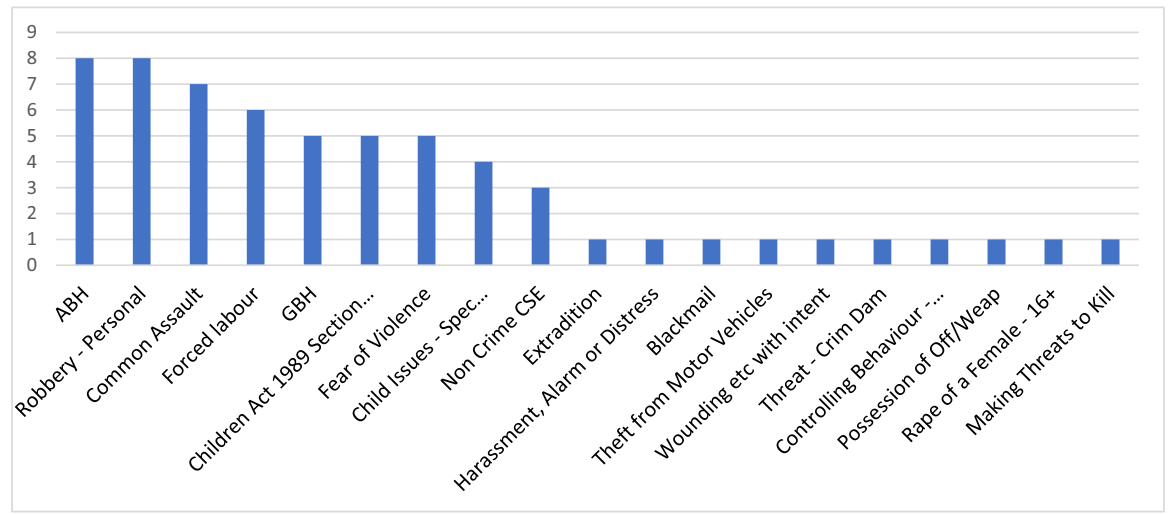

Fig. 3 Numbers of recorded victimisation experiences across the 81 by offence category (partial list)

by a steep decline in participation rates from ages in the early $20 \mathrm{~s}$. (Note that this is not a longitudinal plot of the same individuals at different years, but rather a frequency distribution of different individuals into different age categories in the year 2019).

Figure 3 indicates the victimisation experiences of these 81 offenders. The cohort consisted of 74 males and seven females. The females had on average suffered more ACE experiences than the males with an average of five events vs three events. When the additional eight trauma factors are added, the difference is even greater: an average of nine events vs six events. There are some common themes with these seven females. The Department of Social Services had been aware of all 
their families from birth; all had witnessed serious levels of domestic violence harm; all had been excluded from school, and all had been missing persons. In addition, 71 percent had also been victims of sexual abuse.

The majority of the 81 offenders were African/Caribbean/Other Black (61 percent), with 27 percent White and 12 percent Middle East/South Asian. The White offenders had experienced an average of four ACEs, which was the highest of any ethnic group. The African/Caribbean/Other Black had an average of three ACEs, or $25 \%$ fewer than for the white prolific defendants. The Middle East/South Asian suspects had records of an average of two ACE events known to police. When the additional eight trauma events are added, the numbers rise to seven (white), six (black), and five (Middle East/Asian) respectively.

\section{Victimisation History}

Among the 81 offenders aged under 26 accused of four or more robberies in 2019, 80 percent had been a victim of crime, compared with 64 percent of all the 1249 arrested offenders aged under 26. For those in the cohort who had been a crime victim, the average number of all ACEs was 3.7 compared with 2.5 for those who had not been a victim.

\section{Offending}

In 2019, according to CRIS records, fewer than five percent of robberies resulted in an arrest and charge. Among the 1249 under 26 arrestees, 6.5 percent accounted for 24 percent of all robbery accusations in that age group, and intelligence reports attribute many more offences to them.

Figure 4 displays the number of arrests for robbery in 2019 by 81 offenders in the study cohort. Just over one-third had been arrested only four times (the minimum for inclusion in the cohort), while ten percent had been arrested between 9 and 16 times - all in the year 2019 alone. A total of 80 percent had used a knife or threatened with a knife to commit one or more of their crimes that year. In total, the cohorts were found to have lifetime criminal histories associated with 939 offences covering 34 offence types: The three most common were theft from person (201), possession of drugs (164) and violence with injury (89).

Only five of these offenders (six percent) had always committed their offences alone, while $94 \%$ had offended in groups of two or more. A total of 36 percent had committed their offences in groups of three or more.

Like all the 1249 street robbery offenders aged under 26 arrested in 2019, the most common offences committed by this cohort of 81 were robbery of personal property, possession of drugs and violence with injury.

\section{Experience of ACE and Other Trauma by the Cohort}

Figure 5 examines ACE categories first identified by Felitti et al. (1998) and widely adopted by subsequent ACE researchers, as listed above. Only 12 percent of the 


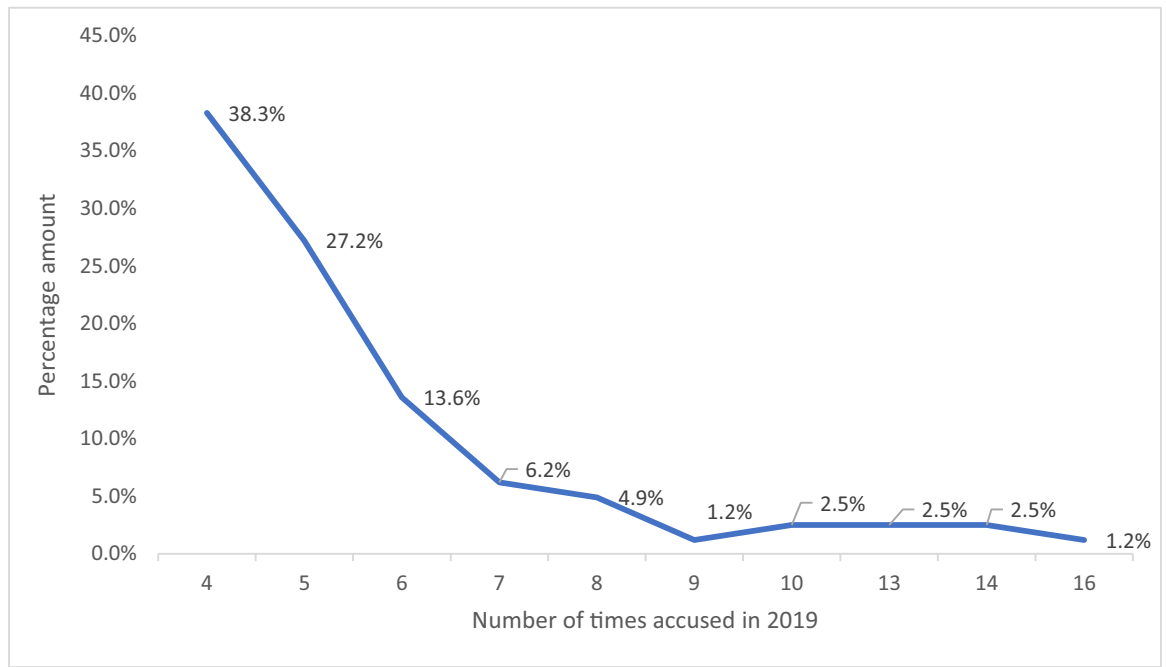

Fig. 4 Cohort arrests for all offences 2019

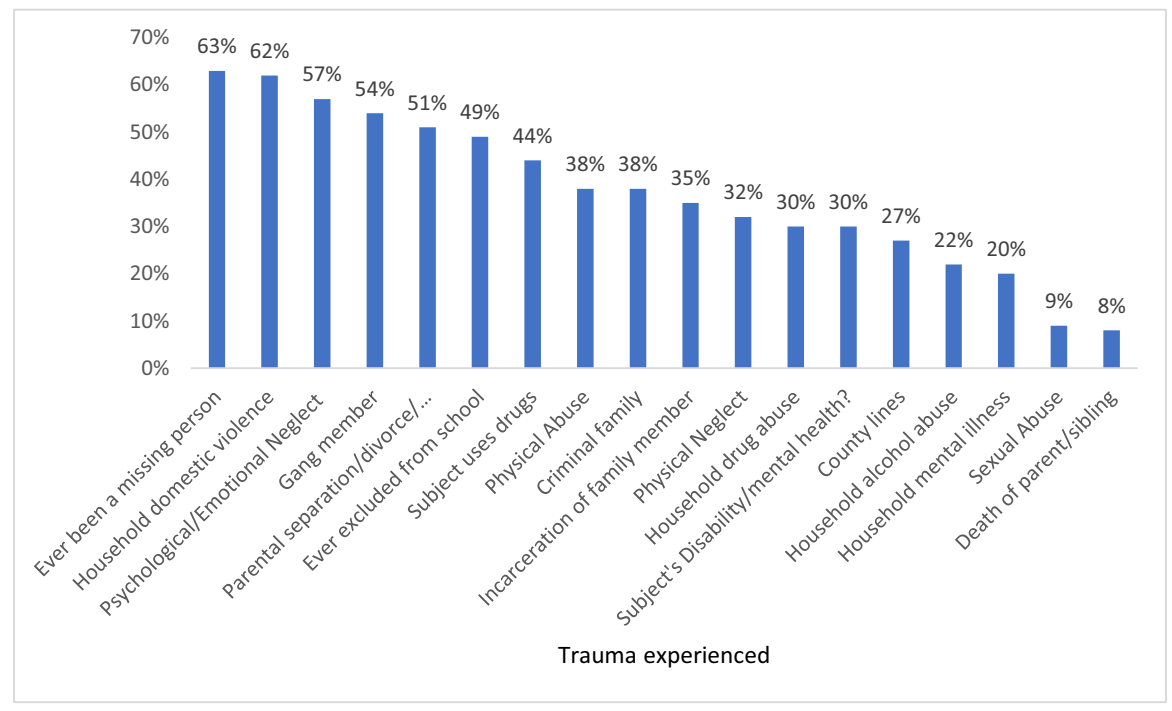

Fig. 5 Percent of the cohort with one or more of each ACE category

MPS cohort were found to have experienced zero events; 12 percent had experienced exactly one (known to police); 25 percent had experienced two or three, and 49 percent had experienced four or more. Almost all of the prolific defendants ( 91 percent) were known to the Department of Social Services (DSS).

Figure 5 shows the percentage of offenders that MPS records indicate had ever (from birth to an upper limit of age 25) experienced each of the ACE factors, together with an additional eight associated trauma factors identified in the records. 
Absent DSS records however, these must represent a minimum estimate of their childhood trauma, based solely on what could be found in police records.

\section{Comparative Prevalence of ACE Factors to a General Population}

Having established the extent of ACE factors and related trauma in the lives of the 81 young robbery offenders in this cohort, the next step is to understand whether and to what extent the cohort exhibited higher than average levels of trauma experience.

The difficulty in answering that question is the very different periods of time covered by the MPS analysis compared to annual rates of population-based ACE events. Comparing the ACE history of a group of 81 people whose ages range from 13 to 26 creates a highly diverse set of years at risk of being reported missing, being excluded from school and other indicators of childhood adversity. The comparison is particularly challenging when the general population statistics are expressed as annual rates, as in school exclusions. We therefore use these comparisons as merely indicative rather than any approaching a precise estimate of the difference in prevalence levels between the 81 and a general population estimate.

Two British studies of ACE incidence (Bullock et al. 2020; Asmussen 2020) have been used to provide baseline information to compare with the incidence of ACE among the cohort of prolific young robbery offenders who are the subject of this study. Both of them acknowledge the difficulties in obtaining accurate information on the prevalence of ACEs and child maltreatment more generally, but the convergence of the two separate population studies in their findings encourages confidence in their findings.

The report of Bullock et al. (2020) followed the setting up in 2018 of England's first Violence Reduction Unit (VRU), which brought police together with specialists from public health, the NHS, probation, safeguarding and other relevant agencies. The VRU commissioned an investigation into the impact of ACEs in London (Bullock et al., 2020). With a sample of 15,431 London children, the study concluded that:

- Around half of Londoners are likely to have experienced at least one form of adverse experience in their childhood.

- Around ten percent of Londoners are likely to have experienced four or more different types of ACE, usually including abuse or neglect.

- The distribution of ACE in London broadly aligns with areas of affluence and deprivation.

- Population groups with a high level of adversity or need in adulthood, including those who are homeless, in prison, have substance misuse issues or serious mental health problems, are more likely to have experienced ACEs than the general population.

A complementary study was undertaken by Asmussen et al. (2020) from the Early Intervention Foundation, an independent charity established to support early intervention in the lives of at-risk young people. Their ACE data was gleaned 
Table 1 Estimates of ACE prevalence

\begin{tabular}{llllll}
\hline Study & Sample & \multicolumn{3}{c}{$\%$ Experiencing ACEs } \\
\cline { 3 - 5 } & & 0 & 1 & $2-3$ & $4+$ \\
\hline Asmussen et al. (2020): England & 399,500 (children in need) & - & 80 & - & $10-20$ \\
Bullock et al. (2020): London & 15,431 (random sample children) & 54 & 20 & 15 & 11 \\
This study (MPS) & 81 (prolific young robbers) & 12 & 14 & 25 & 49 \\
\hline
\end{tabular}

from a number of different sources including a National Society for the Prevention of Cruelty to Children prevalence survey conducted with children and families (Radford et al., 2011) and from adult psychiatric surveys. The study concluded that over 80 percent of the 399,500 children in England estimated in 2019 to be 'in need' had experienced at least one ACE and between 10 and 20 percent may have had four or more ACEs.

Table 1 shows the estimated prevalence of ACE experience in these three studies.

Given the repeated findings of 4 or more ACEs as a tipping point for profound later-life difficulties, we focus the analysis of Table 1 on the percentage of the samples experiencing more 4 or more ACEs. The larger population groups are drawn using two very different methods. Asmussen et al. (2020) purposively drew a sample of children in need across England, in which it would be expected that higher base rates would be found than in the random sample of children in the general London population drawn by Bullock et al. (2020). Nonetheless, they both show far lower prevalence of 4 or more ACEs than the present MPS study of the 81 prolific young robbery suspects.

Combining both the 10-20 range in the all-England children in need study to the $11 \%$ estimate for a random sample of London children yields a range of estimates of how much greater ACE experience there is among the 81 offenders in the MPS robbery cohort. The prevalence of 4 or more lifetime ACEs among the 81 prolific robbery offenders is two to five times higher than it is in the other lifetime estimates.

Table 2 displays the percentage of participants in each of the three available studies who suffered each ACE. It shows that the 81 offenders in this cohort suffered at higher levels on almost every category of ACE. The elevated scores are particularly clear for psychological abuse, physical neglect, family misuse of drugs and alcohol, family members' incarceration and parental separation.

In addition, eight additional variables that may be related to trauma were explored for the current cohort. The analysis shows $49 \%$ of the 81 had been excluded from school (the youngest at the age of six) when the one-year London average for exclusion was $0.1 \%$ of the school population in 2018-2019 (Department for Education 2021). Because the MPS estimates are lifetime measures, however, they are unfortunately not comparable to the one-year London rates.

Table 2 also showed that 63 percent of the 81 had ever gone missing from home, when MPS data indicate the London annual rate for under 25 going missing is 1.05 percent, while the UK annual average for under 25 is 0.6 percent (Missing Children Statistics, 2020). While the comparative rates are annual and the MPS rate for the 
Table 2 Percentage of ACE categories in each study

\begin{tabular}{llll}
\hline ACE factor & $\begin{array}{l}\text { Felitti } \\
(1998) \\
\%\end{array}$ & $\begin{array}{l}\text { Asmussen } \\
(2020) \%\end{array}$ & $\begin{array}{l}\text { Current } \\
\text { (MPS) } \\
\text { Study \% }\end{array}$ \\
\hline Physical abuse & 28 & 15 & 38 \\
Sexual abuse & 21 & 6 & 9 \\
Psychological abuse & 15 & 22 & 57 \\
Physical neglect & 10 & 18 & 35 \\
Mental illness & 17 & 3 & 20 \\
Domestic abuse & 13 & 51 & 63 \\
Drugs/alcohol & 27 & 21 & 40 \\
Incarceration of family member & 6 & - & 35 \\
Parental separation & 23 & - & 52 \\
Psychological neglect & 11 & - & - \\
\hline
\end{tabular}

81 is cumulative across many years, the missing rate would still seem to be much higher for the 81 than for London children generally.

Despite the problematic quality and reliability of the comparative data presented here, it seems incontrovertible that the 81 offenders in this cohort had experienced levels of adverse childhood events substantially higher than even seriously disadvantaged children that were the subject of Asmussen et al.'s (2020) study, as well as Felitti et al.'s (1998) troubled adult subjects and Bullock et al.'s (2020) sample of London children.

Better coordination between police and other agencies with knowledge of their family situation could allow predictive analysis to prioritise resources to the high harm repeat victims, especially when they start offending. Evident from the findings around the prevalence of family criminality (38 percent) and incarceration of family members (35 per cent) is a cycle of offending that needs to be broken (Welsh \& Farrington, 2007).

\section{Conclusions}

Police responses generally focus solely on dealing with offender behaviour, not on understanding their vulnerability or underlying factors related to the offending. One effect of that is that police are unable to 'diagnose' some causes of crime that may be treatable, in more of a 'public health' model of policing.

In 2016, Her Majesty's Inspectorate of Constabulary and Fire \& Rescue Services conducted a review of police child protection practices (HMICFRS, 2016). The 'national child protection post-inspection review' was conducted in 2018, and the subsequent report (HMICFRS, 2019) found that police response often focuses solely on dealing with children's offending behaviour, rather than addressing their vulnerability or analysing historical factors and multi-agency information to help them understand a child's situation. Police may need to consider their role in addressing ACEs, especially in light of this critical report and of the findings of this study. 
As suggested at the outset, one practical strategic approach might be for police to work with NHS Mental Health Trusts to develop and test some form of cognitive behavioural therapy to see if it can reduce further offending. To the extent that a prolific robbery offender is caught up in a social and family network of violence and threat, the therapy may well be overwhelmed by other factors. Yet such therapy could be part of a broader approach to reducing high-frequency crimes of high harms. With only 81 people to engage across a population of 8 million, the level of resources invested to prevent 465 robberies could be substantial but highly cost-effective.

Open Access This article is licensed under a Creative Commons Attribution 4.0 International License, which permits use, sharing, adaptation, distribution and reproduction in any medium or format, as long as you give appropriate credit to the original author(s) and the source, provide a link to the Creative Commons licence, and indicate if changes were made. The images or other third party material in this article are included in the article's Creative Commons licence, unless indicated otherwise in a credit line to the material. If material is not included in the article's Creative Commons licence and your intended use is not permitted by statutory regulation or exceeds the permitted use, you will need to obtain permission directly from the copyright holder. To view a copy of this licence, visit http://creativecommons.org/licen ses/by/4.0/.

\section{References}

Asmussen, K., Fischer, F. Drayton, E. and McBride, T (2020). Adverse childhood experiences, what we know, what we don't know, and what should happen next. https://www.eif.org.uk/report/adver se-childhood-experiences-what-we-know-what-we-dont-know-and-what-should-happen-next. Accessed 2020

Baglivio, M. T., Epps, N., Swartz, K., Huq, M. S., Sheer, A., \& Hardt, N. S. (2014). The prevalence of adverse childhood experiences (ACE) in the lives of juvenile offenders. Journal of juvenile justice, 3(2).

Bullock, M. (2020) Adverse Childhood Experiences in London. Investigating ways that Adverse childhood experiences and related concepts of vulnerability can help us to understand and improve Londoners' health. Public Health Specialty Registrar Greater London Authority, 2019.

Craig, J. M., Piquero, A. R., Farrington, D. P., \& Ttofi, M. M. (2017). A little early risk goes a long bad way: Adverse childhood experiences and life-course offending in the Cambridge study. Journal of Criminal Justice, 53, 34-45.

Craig, J. M., Malvaso, C., \& Farrington, D. P. (2021). All in the family? Exploring the intergenerational transmission of exposure to adverse childhood experiences and their effect on offending Behavior. Youth Violence and Juvenile Justice, 19(3), 292-307.

Department for Education (2021). https://explore-education-statistics.service.gov.uk/find-statistics/ permanent-and-fixed-period-exclusions-in-england . Accessed 14 November 2021.

Farrington, D.P. (1986). 'Age and crime' in Crime and Justice, (ed. M. Tonry), Vol 7. Chicago, University of Chicago Press.

Farrington, D. P., Jolliffe, D., Loeber, R., Stouthamer-Loeber, M., \& Kalb, L. M. (2001). The concentration of offenders in families, and family criminality in the prediction of boys' delinquency. Journal of Adolescence, 24(5), 579-596.

Felitti, V. J., Anda, R. F., Nordenberg, D., Williamson, D. F., Spitz, A. M., Edwards, V., \& Marks, J. S. (1998). Relationship of childhood abuse and household dysfunction to many of the leading causes of death in adults: The adverse childhood experiences (ACE) Study. American Journal of Preventive Medicine, 56(6), 774-786. 
Foa, E. B., \& Meadows, E. A. (1997). Psychosocial treatments for posttraumatic stress disorder: A critical review. Annual Review of Psychology, 48(1), 449-480.

Fox, B. H., Perez, N., Cass, E., Baglivio, M. T., \& Epps, N. (2015). Trauma changes everything: Examining the relationship between adverse childhood experiences and serious, violent and chronic juvenile offenders. Child Abuse \& Neglect, 46, 163-173.

Home Office (2017). Criminal exploitation of children and vulnerable adults: County lines. London.

Lauritsen, J. L., \& Laub, J. H. (2007). Understanding the link between victimization and offending: New reflections on an old idea. Crime Prevention Studies, 22, 55.

Loeber, R., \& Howell, J. C. (2012). Young adult offenders: The need for more effective legislative options and justice processing. Criminology \& Public Policy, 11(4), 729-750.

Malvaso, C. G., Delfabbro, P. H., Day, A., \& Nobes, G. (2018). The maltreatment-violence link: Exploring the role of maltreatment experiences and other individual and social risk factors among young people who offend. Journal of Criminal Justice, 55, 35-45.

Missing Children Statistics (2020). 'The largest missing children statistics in the UK. Accessed in April 2021 at https://perpetualfostering.co.uk/insights/missing-children-statistics-uk-2020_ Date accessed 2.4.21.

Radford, L., Corral, S., Bradley, C., Fisher, H., Bassett, C., Howat, N., \& Collishaw, S. (2011). Child abuse and neglect in the UK today. National Society for the Prevention of Cruelty to Children (NSPCC).

Sherman, L. W. (2007). The power few: Experimental criminology and the reduction of harm. Journal of Experimental Criminology, 3(4), 299-321.

Welsh, B. C., \& Farrington, D. P. (2007). Save children from a life of crime. Criminology \& Public Policy, 6, 871 .

Wikström, P. O. H., Oberwittler, D., Treiber, K., \& Hardie, B. (2012). Breaking rules: The social and situational dynamics of young people's urban crime. OUP Oxford.

Publisher's note Springer Nature remains neutral with regard to jurisdictional claims in published maps and institutional affiliations.

\section{Authors and Affiliations}

\section{Lorraine Hilder $^{1} \cdot$ Heather Strang ${ }^{2}$. Sumit Kumar}

Heather Strang

hs404@cam.ac.uk

1 Metropolitan Police Service, London, UK

2 Jerry Lee Centre of Experimental Criminology, Institute of Criminology, University of Cambridge, UK, Cambridge 